\title{
FEELINGS AND REACTIONS OF MEN AND WOMEN TO THE COVID 19 PANDEMIC IN BRAZIL
}

\author{
Renata da Silva Coelho, Joice Aparecida Araujo Dominguez, Helena Rinaldi Rosa, \\ \& Leila Salomão de La Plata Cury Tardivo \\ Psychology Institute - Universidade de São Paulo (Brazil)
}

\begin{abstract}
This current study aims to understand the impacts of the pandemic on a group of adult men and women's mental health. Social distancing, the fear of getting sick, the loss of the loved ones and changes in the family's routine triggered and favored the difficulties increase in the population's mental health. This study presents data related to the online survey carried out from April to October among men and women in Brazil, through an electronic form, recording the effects of isolation, the main complaints and the feelings that permeate everyone. Both men and women over the age of 18 constitute part of the active population and an age group which assumes many responsibilities and was, on a large scale, affected by the pandemic. Out of the 6,766 people over the age of 18 that participated in the survey, 6,023 were female and 743 were male. Most women were aged between 31 to 40 and most men, 21 to 30 . The main feelings reported by the participants appeared in the following order: fear, sadness, irritation, solidarity, overload, hope, loneliness and optimism for women and fear, irritation, sadness, overload, solidarity, loneliness, hope and optimism for men. It was concluded that in the pandemic period, people experienced constant and significant changes in the social and technological fields in an impacting way and without any choice. The pandemic caused intense psychic distress in people, highlighting the need for therapeutic and preventive work to return to activities and for the population's mental health.
\end{abstract}

Keywords: Feelings, pandemic, social distancing, isolation.

\section{Introduction}

In March 2020, the World Health Organization (WHO) declared the new coronavirus Covid-19 a global pandemic which caused distancing and social isolation in many countries. In Brazil, more than 5 million cases of the disease were confirmed in mid October 2020. Social distancing, the fear of getting sick, the loss of the loved ones and changes in the family's routine triggered and favored the difficulties increase in the population's mental health. This is considered the fourth wave in the health sphere. Therefore, part of the control actions to face the pandemic is that men and women follow the authorities' prevention recommendations.

The entire Brazilian population, both men and women, were abruptly affected, being unable to go to their workplaces, many of them adapting to working at home, online classes, without any contact with friends also having a very intense and challenging coexistence with family members at home as well as greater use of social networks and technology. These factors require more attention in the pandemic which represents an important state of emotional and social vulnerability, making it difficult to maintain a balanced psychic structure.

On the other hand, several programs and services in the country tried to seek understanding of the current moment in order to contribute to a better psychological care for the population in general. Among these services, authors proposed the online survey, which was made feasible by the psychological care project of the Mental Health and Social Clinical Psychology Laboratory of IPUSP (USP Institute of Psychology), APOIAR. It aimed at identifying people's suffering in the pandemic and social distancing through a survey on the impact of the pandemic on people's daily lives, mainly on their mental health, focusing on finding out the principal emotional difficulties (loneliness, sadness, dejection, depression, deep fears, anguish, anxiety or conflicts) of the population including men and women. This study presents data related to the online survey carried out from April to October among men and women, recording the effects of isolation, the principal complaints and the main feelings that permeate everyone. Both men and women over the age of 18 constitute part of the active population and an age group which assumes many responsibilities and was, on a large scale, affected by the pandemic in a more disturbing way, in many senses. 


\section{Objectives}

This current study aims to understand the impacts of the pandemic on a group of adult men and women's mental health, who are over the age of 18.

\section{Methods}

Considering the importance of knowing the social isolation and distancing impacts resulting from the COVID-19 pandemic, Google Forms questionnaires were prepared for men and women and shared online through social networks in order to understand the current situation regarding men's feelings and attitudes.

Out of the 6,766 people over the age of 18 that participated in the survey, 6,023 were female and 743 were male. Most women were aged between 31 to 40 and most men, 21 to 30 . The majority of the participants are from the capital of São Paulo (69.4\% of women and 70.1\% of men) from April to October 2020.

\section{Results and discussion}

6,023 women and 743 men ranging from 19 to over 80 years participated in the survey, being adults from 21 to 50 predominant. Most participants were from São Paulo, but there are responses from residents in different Brazilian states. Convenience sample and snowball subject recruitment were the methods used. The most relevant results show that $50.1 \%$ of men and $53.7 \%$ of women have children. In addition to working, most women carry out domestic chores (cooking, washing etc.) and help their children with online school activities; men work and also perform chores at home, but less frequently than women. Fear is the most predominant feeling among women and men followed by irritation for men and sadness for women. The most frequent feeling is inverted in the third position: sadness for men and irritation for women. The feelings of overload and solidarity are in $4^{\text {th }}$ position for both (more frequent among women). The research presented important indicators of the emotional state resulting from the impacts of the pandemic on the general population, which can contribute to mental health care strategies during and after the Covid-19 pandemic in Brazil.

The age of the male participants ranged from 21 to 30 years, closely followed by the 41-50, 31-40 and 51-59 age ranges. Most participants in this group have a higher education level and paid or voluntary work. More than $50 \%$ have children given that just over $50 \%$ have 2 to 3 children followed by the ones who have 1 child. Just over $50 \%$ of children are over 18 years old, and in the other age groups they are distributed in a more balanced way with fewer babies under 1 year old. The vast majority do not have grandchildren.

Regarding social isolation, at the time the questionnaire was shared, most participants had been together with 2 to 3 people for more than 15 days, followed by isolation in 2 people and the participant being by him or herself. The vast majority agrees with isolation, even fewer people partially agree. There were few responses against the protection measure and even fewer participants stated that they were indifferent to the issue. Most of the participants are working at home and consider using social networks much more in this period than before. Nearly all of them use WhatsApp followed by e-mail and YouTube, Facebook and Instagram. Almost all participants use these apps to talk to friends followed by checking the news, talking to family members, watching movies, playing games and working.

Among male participants, $69 \%$ reported that they currently reside in São Paulo, other Brazilian states $31 \%$ and less than $1 \%$ in countries abroad, including Portugal, England, Spain and Austria.

In isolation, the vast majority of men stated that they are doing a lot of domestic chores, such as cooking, cleaning the house, washing and ironing followed by reading, leisure activities and playing and helping children with school activities to a lesser extent. They consider to be in harmony with their families at this moment and that isolation is bringing them closer (though less than 50\%). These participants state they have conflicts which already existed before the pandemic, followed by those who consider to have some conflicts that occur or are worsened due to the daily proximity in isolation. The majority of the participants stated that they have feelings as never before, with the predominance of fear, followed by irritation, solidarity, sadness, overload, hope, loneliness and anxiety; and yet the vast majority associates them directly with the pandemic.

Regarding sleep, male participants stated they have a good and reasonable quality (closer), fewer stated this quality is bad, and just over $50 \%$ stated they notice a change in sleep during this period.

More than $50 \%$ of the participants stated that they did physical activities before the pandemic, but did not maintain the same practice during the period. Most of the participants who followed psychological care before the pandemic suspended it during this period, followed by those who managed 
to maintain online sessions during the pandemic. Most participants state that talking to a psychologist could not help at this time, followed very closely by those who state that talking to a psychologist could surely help at this time and the other part which considers it might help or not. The vast majority (almost all) stated they thought the pandemic was going to change their lives in some way.

For women, age ranges between 31 and 40 years, followed closely by 41-50, 21-30, and 51-59 age ranges. Most participants in this group have a higher education level and paid or voluntary work. More than $50 \%$ have children, just over half participants have 2 to 3 children followed by the ones who have 1 child. Just over $50 \%$ of children are over 18 years old, and in the other age groups they are distributed in a more balanced way with fewer babies under 1 year old. The vast majority do not have grandchildren. At the time the questionnaire was shared, most participants had been with 2 to 3 people for more than 15 days, followed by isolation in 2 people and the participant being by him or herself. Regarding isolation, the vast majority agreed with social distancing, even fewer women who partially agree and none who is against the measure. Most of the participants are working at home and consider using social networks much more in this period than before. Nearly all of them use WhatsApp followed by Instagram and YouTube. This use refers more to talking to friends, almost all, followed by checking the news, games and working. During social distancing, the vast majority of women stated that they are performing many domestic chores, such as cooking, cleaning the house, washing and ironing followed by leisure activities, playing and helping children with school activities which appear at a lesser extent. More than $50 \%$ state they have to help with the mentioned activities. They considered being in harmony with their families at this moment (though less than 50\%). They stated that they have conflicts that already existed before the pandemic, followed by those that either started to happen or worsened in this period. The vast majority of the participants stated that they have feelings as never before with the predominance of fear, followed by irritation, overload, loneliness and anxiety; and yet the vast majority associates them directly with the pandemic.

The participants answered about the place they currently reside and 72\% informed São Paulo, other Brazilian states represent $27 \%$ of the responses and countries abroad $1 \%$ including the United States, Germany, Portugal, United Kingdom, France, Canada, Sweden, Spain, Costa Rica, Switzerland, Panama, Norway, Italy, Ireland, England, Dubai, Chile, Bolivia and Uruguay.

Regarding sleep, the participants stated that they have a good and reasonable quality (closer), fewer participants stated the quality is bad, and just over $50 \%$ stated they noticed a change in sleep during this period. More than half of the participants stated that they did physical activities before the pandemic, but did not maintain it during the period. Participants who had psychological assistance before the pandemic are evenly distributed between keeping it online during the pandemic or having it suspended. Half of the participants stated that talking to a psychologist could help at this time and the other half is divided into considering that it might help or not. Finally, the vast majority (almost all) state that they believe the pandemic is going to change their life in some way.

\section{Conclusions}

The main feelings reported by the participants were, in general, as follows: fear, sadness, irritation, solidarity, overload, hope, loneliness and optimism for women and, fear, irritation, sadness, overload, solidarity, loneliness, hope and optimism for men. One might conclude that in the pandemic period, people experienced constant and significant changes in the social and technological fields in an impacting way and without any choice. The pandemic provoked new forms of organization, contact and interaction in human beings and has truly potentiated manifestations of intense psychological distress in people, highlighting the need for therapeutic and preventive work for the return to activities and for the population's mental health.

During the research and in the online appointments carried out by the team, it was observed women participated much more than men. Therefore, the reasons why they do not look for health services are: since the male gender is related to the values of culture, the way men build and experience their masculinity becomes one of the matrixes of the ways to get sick and die (LEVORATO et al, 2014). Men also look for services less frequently because they feel embarrassed as this is opposite to the androcentric culture (SILVA et al, 2012).

Regarding the female participants' responses, in the vast majority, both in this survey and seeking care, there were signs of emotional difficulties, such as anxiety, overload, and even depression, as seen in several studies, which still add a feeling of generalized panic and stress in mental health.

Recent researches have shown a higher prevalence of symptoms for stress, anxiety and depression in the female population during the COVID-19 pandemic as pointed out in a Brazilian study (Souza et al, 2020). 
Literature review studies point out that unexpected changes in the family dynamics, such as closing schools, companies and public places and limiting or even prohibiting the practice of physical and leisure activities, changes in routines and work like working at home as well as distancing lead the general population to the feelings of abandon and insecurity due to the economic and social repercussions caused by the pandemic (Moreira et al, 2020).

In another review article Schmidt, Crepaldi, Bolze, Neiva-Silva, \& Demenech (2020) found that the fast worldwide spread of the new coronavirus, the uncertainties about how to control the disease and the seriousness of COVID- 19 in addition to the unpredictability of the pandemic duration and its consequences represent risk factors for the mental health of the general population (Zandifar \& Badrfam, 2020). The same authors describe the broad study by Wang et al. (2020) with the general population in China, including 1,210 participants in 194 cities, during the initial stage of the pandemic. This study showed moderate to severe symptoms of anxiety, depression and stress in $28.8 \%, 16.5 \%$ and $8.1 \%$ of respondents, respectively. Moreover, $75.2 \%$ of the respondents reported fear of their family members contracting the disease. Being a woman, student and having physical symptoms related to COVID-19, or previous health problems, were factors significantly associated with higher levels of anxiety, depression and stress. (Wang et al., 2020). The new coronavirus pandemic can impact mental health and psychological well-being also due to changes in routines and family relationships (Cluver et al., 2020; Ornell et al., 2020) as found in the present investigation.

As measures to combat COVID-19, social or physical distancing stands out (Faro, Bahiano, Nakano, Reis, Silva, \& Vitti, 2020) which implies the maintenance of a spatial distance - about two meters - from people. It is also recommended not to have group meetings and avoid full places and crowds. This measure has been implemented by countries to avoid contagion. Other measures are quarantine and isolation. Quarantine is essential to mitigate contagion, as it is an attempt to keep people out of contact with others, in order to decrease contamination and, consequently, the number of deaths and the demand for health services. Even though it is necessary, quarantine can cause, as the investigation showed, friends' and family's distancing, uncertainty about how long distancing will last (Brooks et al, 2020), boredom (Barari et al 2020), fear (Lima et al, 2020) among others. Also in the mentioned study (Faro, Bahiano, Nakano, Reis, Silva, \& Vitti, 2020), it was observed a greater presence of anxiety disorders (Barari, et al; Lima et al, 2020) and depression (Pancani, Marinucci, Aureli, \& Riva, 2020).

The present investigation showed, like others that have been developed, although with a lesser number of participants, the impacts on mental health in the face of the pandemic in the Brazilian population, considering the characteristics of different populations affected by COVID-19, such as men and women, differences by age and mainly of people and groups in greater vulnerability, women of working age. The need for urgent preventive measures with regard to COVID 19 was highlighted, as well as mental health care and prevention.

The present investigation had a large number of participants, most of them from the State of São Paulo, and showed the impacts on mental health, emotions and attitudes, resulting from the pandemic and measures to combat COVID-19. Considering the greater number of female participants, differences by age, with the largest young adults group, the need for urgent preventive measures to combat COVID-19 as well as mental health care and prevention were highlighted. It is necessary to implement proposals in the view of what the psychological repercussions of the necessary distancing / isolation cause, and the increase of COVID 19 so that it is less harmful.

\section{References}

Barari, S., Caria, S., Davola, A., Falco, P., Fetzer, T., Fiorin, S., Slepoi, F. R. (2020). Evaluating COVID-19 public health messaging in Italy: self-reported compliance and growing mental health concerns.

Brooks, S. K., Webster, R. K., Smith, L. E., Woodland, L., Wessely, S., Greenberg, N., \& Rubin, G. J. (2020). The psychological impact of quarantine and how to reduce it: rapid review of the evidence. The Lancet, 395(102227), 912-920

Cluver, L., Lachman, J. M., Sherr, L., Wessels, I., Krug, E., Rakotomalala, S., \& McDonald, K (2020). Parenting in a time of COVID-19. The Lancet.

Faro, A., Bahiano, M. D. A., Nakano, T. D. C., Reis, C., Silva, B. F. P. D., \& Vitti, L. S. (2020). COVID-19 e saúde mental: a emergência do cuidado. Estudos de Psicologia (Campinas), 37.

Levorato, C. D., Mello, L. M. D., Silva, A. S. D., \& Nunes, A. A. (2014). Fatores associados à procura por serviços de saúde numa perspectiva relacional de gênero. Ciência \& saúde coletiva, 19, 1263-1274. 
Lima, C. K. T., Carvalho, P. M. M., Lima, I. A. S., Nunes, J. A. V. O., Saraiva, J. S., Souza, R. I., ... Rolim Neto, M. L. (2020). The emotional impact of coronavirus 2019-Ncov (new Coronavirus Disease). Psychiatry Research, 287, e11291

Moreira, Wanderson Carneiro, Sousa, Anderson Reis de, \& Nóbrega, Maria do Perpétuo Socorro de Sousa. (2020). Adoecimento Mental na População Geral e em Profissionais de Saúde durante a Covid-19: Scoping Review. Texto \& Contexto - Enfermagem, 29, e20200215. Epub September 02, 2020.

Ornell, F., Schuch, J. B., Sordi, A. O., \& Kessler, F. H. P. (2020). "Pandemic fear" and COVID-19: Mental health burden and strategies. Brazilian Journal of Psychiatry.

Pancani, L., Marinucci, M., Aureli, N., \& Riva, P. (2020). Forced social isolation and mental health: a study on 1006 Italians under COVID-19 quarantine. PsyArXiv Preprints.

Schmidt, B., Crepaldi, M. A., Bolze, S. D. A., Neiva-Silva, L., \& Demenech, L. M. (2020). Impactos na Saúde Mental e Intervenções Psicológicas Diante da Pandemia do Novo Coronavírus (COVID-19)

Silva, P. A. D. S., Furtado, M. D. S., Guilhon, A. B., Souza, N. V. D. D. O., \& David, H. M. S. L. (2012). A saúde do homem na visão dos enfermeiros de uma unidade básica de saúde. Escola Anna Nery, 16(3), 561-568.

Silva, P. A. D. S., Furtado, M. D. S., Guilhon, A. B., Souza, N. V. D. D. O., \& David, H. M. S. L. (2012). A saúde do homem na visão dos enfermeiros de uma unidade básica de saúde. Escola Anna Nery, 16(3), 561-568. Souza

Souza, A. S. R., Souza, G. F. D. A., \& Praciano, G. D. A. F. (2020). A saúde mental das mulheres em tempos da COVID-19. Revista Brasileira de Saúde Materno Infantil, 20(3), 659-661.Qiu J, Shen B, Zhao M, Wang Z, Xie B, Xu Y. A nationwide survey of psychological distress among Chinese people in the COVID-19 epidemic: implications and policy recommendations. General psychiatry [Internet]. 2020[cited 2020 de May de 06].

Wang, C., Pan, R., Wan, X., Tan, Y., Xu, L., Ho, C. S., \& Ho, R. C. (2020). Immediate psychological responses and associated factors during the initial stage of the 2019 coronavirus disease (COVID-19) epidemic among the general population in china. International Journal of Environmental Research and Public Health, 17(5), 1729.

Zandifar A, Badrfam R. Iranian mental health during the COVID-19 epidemic. Asian J Psychiatr. 2020 Jun;51: 101990. doi: 10.1016/j.ajp.2020.101990. Epub 2020 Mar 4. PMID: 32163908; PMCID: PMC7128485. 